\title{
Editorial
}

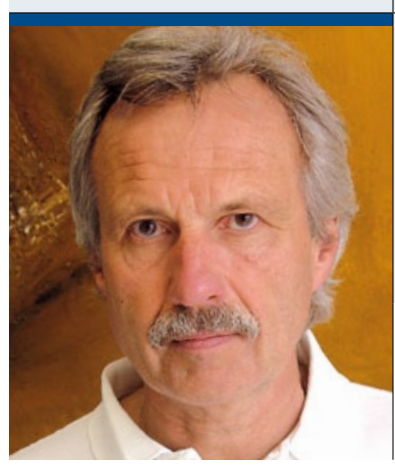

"Wie kann man eine potenziell renitente Ärzteschaft wieder

in die Fron zwingen? Natürlich mit dem altprobaten Mittel

der Verunglimpfung!"

Dr. med. Michael Pieper (Chefredakteur),

Orthopäde am Endocenter Damme

\section{Tango korrupti}

$\mathrm{D}$ as Gezeter und Wutgebrüll nach höchstrichterlicher Entscheidung zur Freiberuflichkeit des Ärztestandes ist symptomatisch. Da droht dem Vertragsarzt die Flucht aus dem Netz öffentlich rechtlicher Regelungsmanie zu gelingen. Das am lautesten von Krankenkassen und Politik angestimmt Lamento lässt auf Entzugsängste schließen. Denn der ungehinderte Zugriff auf die Akteure des Gesundheitswesens gerät in Gefahr. Schließlich ist das Gesundheitswesen eine Säule des Sozialstaates. Mit solch einem Monument lässt sich trefflich reüssieren: Die Kassen nutzen es finanziell und die Politik ideell beim Stimmenfang im Wahlkampf.

Wie kann man eine potenziell renitente Ärzteschaft wieder in die Fron zwingen? Natürlich mit dem altprobaten Mittel der Verunglimpfung: Alle Ärzte sind mutmaßlich korrupt, geldgierig sowieso und setzen dadurch das Leben ihrer Patienten aufs Spiel. Ergo muss die Gesetzeslage verschärft werden. Und zwar so, dass den Medicus allein das Denken an Geld schon in den Knast bringt. So fordert die Staatsanwaltschaft die Einrichtung von Schwerpunktstaatsanwaltschaften zur Bekämpfung von Vermögensstraftaten und Korruption im Gesundheitswesen.

Der politikgesponserte Harvardstudent mit eingebildeter Fachkompetenz nebst bezahltem Einfluss bei Rhön-Kliniken, AOK und Barmer reklamiert „dass die bestehende Rechtsgebung zur Korruption von Amtsärzten nicht ausreicht“ (SZ Nr. 143). Wer ist hier eigentlich Amtsarzt? Da ist der Wunsch Vater des Gedanken!

Die Kassen wollen korruptes Verhalten strafrechtlich fassen. Die KKH-Allianz fordert Gefängnis statt Vertragsstrafen. Die Sanktionswerkzeuge der ärztlichen Aufsichtsgremien bis zum Ruhen der Approbation und damit den Verlust der beruflichen Existenz, genügen den Kassen nicht. Wenn der Arzt nicht hört, gehört er in den „Knast“.

Die „Grünen“ wollen verhindern, dass aus Profitgier unnötige Leistungen verordnet werden. Die
„Linke“ will Bestechung und Bestechlichkeit ahnden. Es gab schon Anzeigen wegen Bestechlichkeit bei mehrmaligen Aut-idem-Verordnungen zugunsten eines Pharmaherstellers. Die Definition der Korruption wird erwartungsgemäß schwammig sein, die strafrechtliche Relevanz damit Ubiquität: keine ärztliche Handlung ohne Anwalt.

Die Brut scheinheiliger Pharisäer, die verurteilen ohne urteilen zu können, hat Konjunktur in diesem Land. Genügt überhaupt der Handlungsspielraum eines Arztes, um durch Korruption den proklamierten Schaden anrichten zu können? Kein Arzt kann verschreiben was er will und wird er noch so schön „geschmiert“! Das betrifft nicht nur sämtliche Facetten der Behandlung, sondern auch der Diagnostik.

Und was ist mit Kassen, die Ärzten Prämien für die DMP-Teilnahme ihrer Patienten gezahlt haben? Oder Ärzte durch massive Einflussnahme zur kostengünstigsten Behandlungsvariante drängen? Wo bleibt denn da das Vertrauensverhältnis zwischen Arzt und Patient? Und wer zahlt die zum Erhalt der Kassenzulassung geforderten Fortbildungen und Kongresse? Ohne Industrieunterstützung gäbe es sie nicht! Da glänzen Krankenkassen und Politik mit vornehmer Zurückhaltung. Alles Korruption?

Warum steigen eigentlich die Patientenzahlen stetig, wenn die Kranken doch durch den Sumpf der Korruption jedes Zutrauen in die mafiöse Ärzteschaft verloren haben? Wäre das Urteil anders ausgefallen, hätte ein direktes Rechtsverhältnis die Ärzte zu Bütteln der Krankenkassen gemacht. Die globale Verunglimpfung zum Zweck der Repression ist ebenso perfide wie echte Korruption.

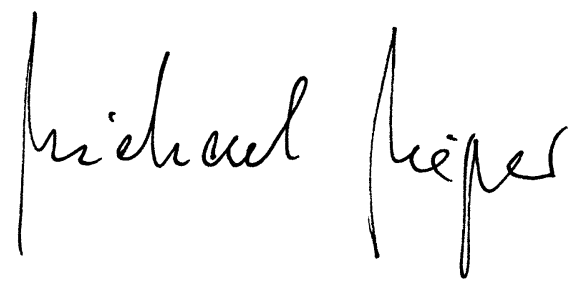

